\title{
Temporal Chondroblastoma with a Novel Chromosomal Translocation (2;5) (q33;q13)
}

\author{
Andrew P. Carlson, M.D., ${ }^{1}$ Howard Yonas, M.D., ${ }^{1}$ Garth T. Olson, M.D., ${ }^{2}$ \\ Kaaren K. Reichard, M.D., ${ }^{3}$ and Rafael Medina-Flores, M.D. ${ }^{3}$
}

The case of a 51-year-old man with a large temporal mass is presented. The mass eroded the floor of the middle fossa medially to the sphenoid sinus. A combined approach with neurosurgery and otolaryngology was performed to achieve maximal resection of the mass. Pathology was typical for chondroblastoma: a rare, benign but locally invasive chondroid tumor. Genetic testing revealed a translocation of $(2 ; 5)$ (q33; 113$)$. This is a unique genetic mutation in all chondroid tumors to our knowledge. The diagnostic utility or role of this mutation in the pathobiology of this tumor remains to be determined.

KEYWORDS: Chondroblastoma, genetics, karyotype, temporal bone, skull-base tumor, cytogenetics

\section{CASE REPORT}

A 51-year-old man presented with a history of a mass on the right side of the face and had previously undergone an open biopsy at an outside facility; the mass was revealed to be a chondroblastoma. His primary complaints at the time of initial evaluation were headache, blurry vision, pain, and numbness on the right side of the face as well as generalized fatigue. Imaging revealed a destructive mass eroding from the infratemporal fossa into the middle fossa and medially into the sphenoid sinus (Fig. 1). The mass also displaced the lateral orbital wall medially. A combined surgical approach with neurosurgery and otolaryngology was recommended to resect as much of the tumor as possible. Preoperative exam and workup revealed severely decreased sensation in V1 and V2 (first and second trigeminal nerve divisions) distributions on the right as well as severe mixed hearing loss demonstrated by audiology. Ophthalmologic evaluation revealed right eye proptosis without vision loss.
The patient was taken for resection of the lesion via a right frontal craniotomy, extended preauricularly into the cervical region. The zygoma was reflected inferiorly with the temporalis flap. A frontotemporal craniotomy was performed, revealing the tumor expanding and eroding the temporal bone and sphenoid wing. The dura was opened to inspect for intradural extension and found to be clear of tumor, so was reclosed in a watertight fashion. The otolaryngology team then dissected the mandibular head and temporomandibular joint (TMJ). This glenoid plane appeared to be the origin of the tumor. A thin layer of cortical bone and tumor was dissected away from the temporal dura as well as the lateral orbit all the way down the sphenoid bone to the superior orbital fissure and into the sphenoid sinus (Fig. 2). The V1 and V2 branches were isolated in floor of the middle fossa. The tumor encased these nerves but did not infiltrate into the cavernous sinus, and so the nerves were sacrificed and the tumor was removed from the lateral cavernous sinus wall. The tumor invaded the
${ }^{1}$ Department of Neurological Surgery; ${ }^{2}$ Division of Otolaryngology, Department of Surgery, and ${ }^{3}$ Department of Pathology, University of New Mexico, Albuquerque, New Mexico.

Address for correspondence and reprint requests: Rafael MedinaFlores, M.D., Department of Pathology, MSC08-4640, 1 University of New Mexico, Albuquerque, NM 87131 (e-mail: rmedina-flores@ salud.unm.edu).
Skull Base Rep 2011;1:65-70. Copyright (C) 2011 by Thieme Medical Publishers, Inc., 333 Seventh Avenue, New York, NY 10001, USA. Tel: +1(212) 584-4662.

Received: December 17, 2010. Accepted: January 10, 2011. Published online: March 25, 2011.

DOI: http://dx.doi.org/10.1055/s-0031-1275638.

ISSN 2157-6971. 
A
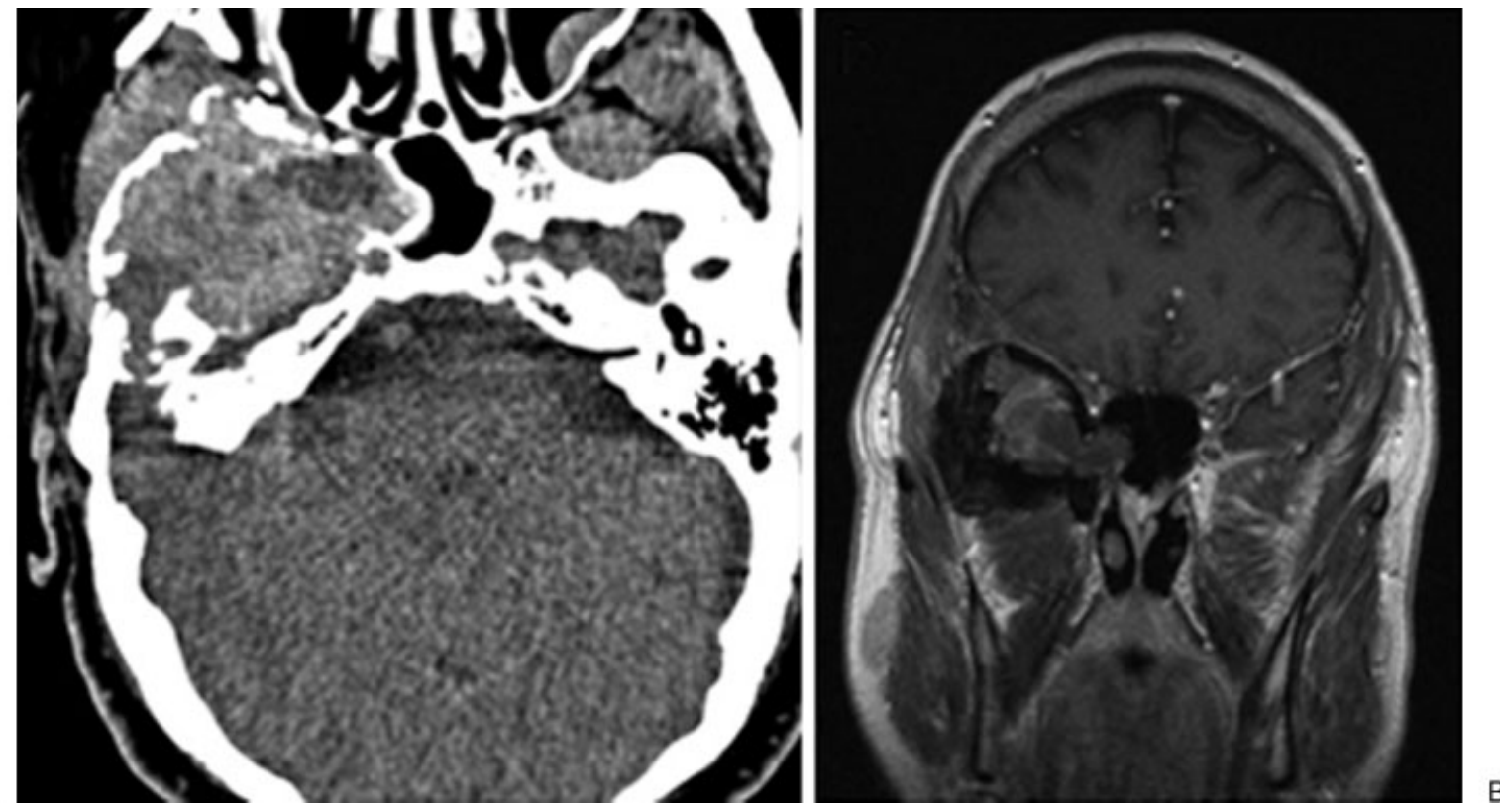

Figure 1 (a) Noncontrasted, axial computed tomography scan through the skull base showing the erosive lesion in the floor of the right middle fossa. The mass is seen extending to the carotid canal and into the sphenoid sinus. (b) Postcontrast, T1weighted coronal magnetic resonance imaging showing no significant enhancement of the lesion and its relationship to the infratemporal and middle fossae.

petrous temporal bone and was removed medially, exposing the petrous carotid artery and eustachian tube. After curetting out the petrous bone surrounding the carotid artery, no further gross tumor was seen. The skull base was reconstructed using two vascularized flaps. The sphenoid sinus was filled with an extended temporalis muscle flap and covered with DuraSeal (Coviden, Mansfield, MA). A vascularized periosteal graft was then laid across the exposed petrous air cells and covered with DuraSeal. A titanium mesh cranioplasty was secured in place.

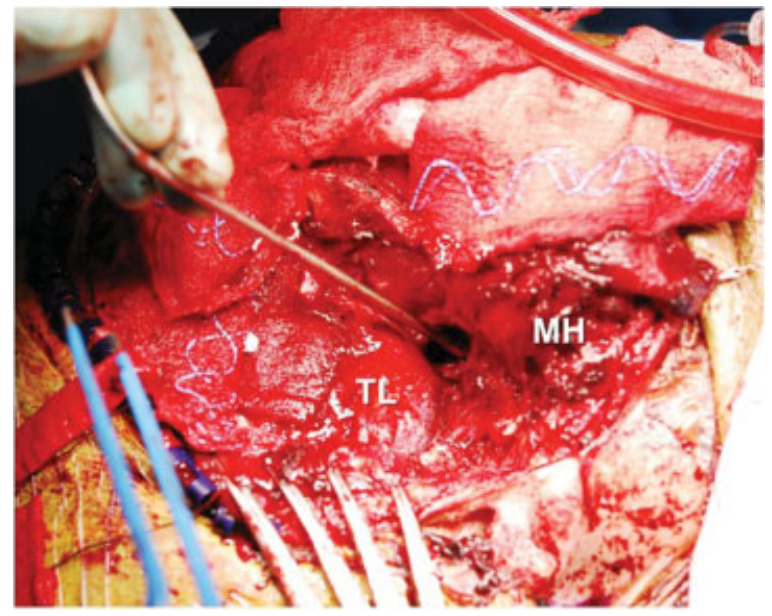

Figure 2 Intraoperative photograph. The suction is pointing out the resection through the lateral wall of the sphenoid sinus. $\mathrm{MH}$, mandibular head; $\mathrm{TL}$, temporal lobe.
Gross examination of the lesion showed multiple, fragmented tissue types, with osseous as well as soft, reddish-purple necrotic portions. Microscopic examination showed a typical appearance of chondroblastoma, with many multinucleated giant cells against a chondroid background. There were portions of cortical bone that the tumor abutted and invaded (Fig. 3).

Karyotyping revealed a male chromosome complement with translocation $\mathrm{t}(2 ; 5)$ was present in 9 of 20 cells analyzed (Fig. 4). Eleven cells had a male chromosome complement with no clonal abnormalities detected.

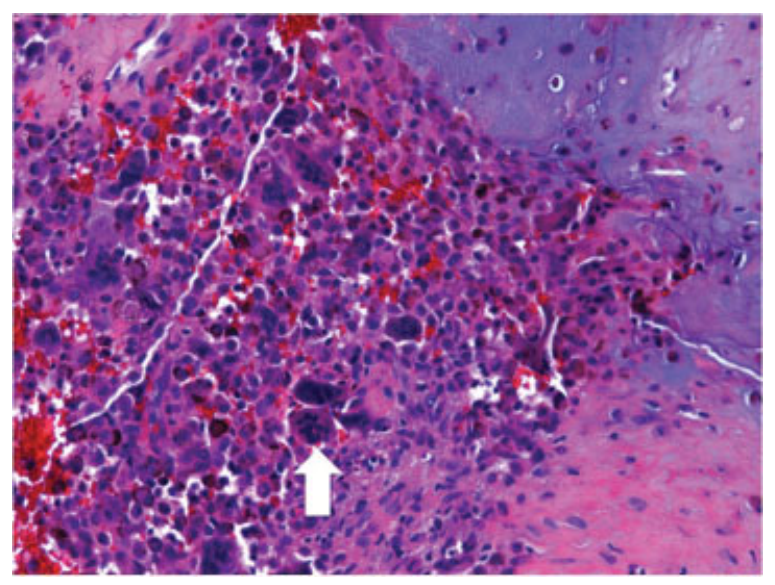

Figure 3 Representative section, hematoxylin and eosin, $200 \times$ magnification. Typical multinucleated giant cells can be seen (white arrow) against a hemorrhagic chondroid background. Areas where the tumor abuts the osseous component can also be seen. 

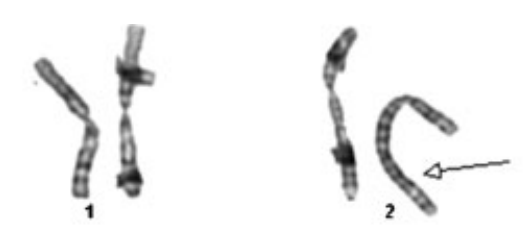
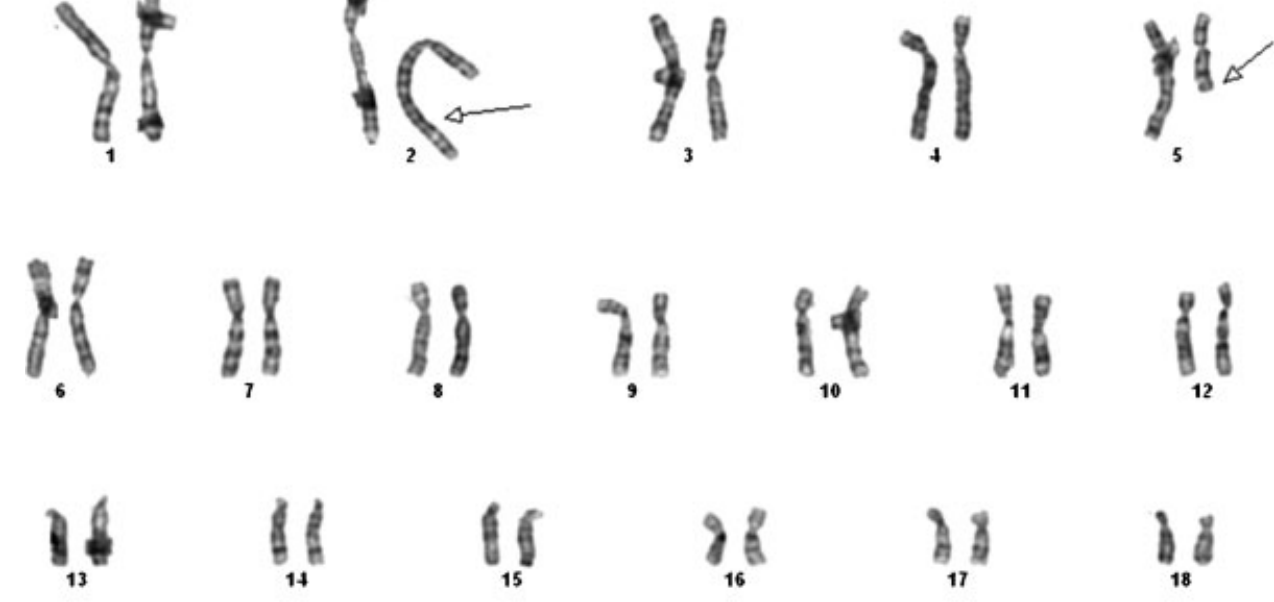

${ }_{22}^{18}$

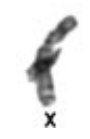

Figure 4 Karyotype 46,XY, t(2;5)(q33;q13)[9]/46,XY[11].

Cytogenetic studies were performed on tumor cells using short-term unstimulated cultures set up on the same day of the surgery. Metaphases were Giemsa (G)-banded by conventional G-bands by trypsin using Wright stainbanding and at least 20 metaphases were analyzed. ${ }^{1}$

\section{LITERATURE REVIEW}

Temporal bone chondroblastoma is a rare tumor in the skull base with $\sim 75$ cases reported worldwide. ${ }^{2,3}$ Though generally considered benign, ${ }^{2}$ it can have locally aggressive features, ${ }^{3,4}$ and recurrence after resection is around 20\%. ${ }^{5}$ Chondroblasts and multinucleated giant cells in a chondroid matrix are diagnostic. ${ }^{2}$ The squamous temporal bone, especially the glenoid region, ${ }^{6}$ embryologically has a cartilaginous origin, making this a potential site of growth. Reflecting this cartilaginous origin, the tumors typically stain for S-100 and vimentin. $^{2,3,7-9}$ Fine-needle aspiration of these lesions can be misleading ${ }^{10}$; temporal bone chondroblastomas need to be distinguished from giant cell tumor of bone, chondromyxoid fibroma, and osteosarcoma. Petrous location, ${ }^{11,12}$ as well as mandibular ${ }^{13,14}$ and less commonly, other craniofacial locations, have also been reported. ${ }^{15-18}$ Radiographically and pathologically, cystic degeneration is common. ${ }^{3,17,19,20}$ Though small lesions occasionally are reported, ${ }^{3,21}$ extensive local invasion of the middle fossa, TMJ, and petrous bone is typical. ${ }^{21-24} \mathrm{~A}$ single report of intracranial hemorrhage related to skull chondroblastoma exists. ${ }^{25}$

Recommended treatment is surgical with total resection. 3,5,6,26,27 The potential areas of difficulty with total resection have been pointed out to be at the TMJ as well as at the dural interface. ${ }^{3}$ Though true dural invasion is uncommon, it can occur, necessitating careful inspection. ${ }^{23}$ Familiarity with skull base approaches, techniques, and anatomy allows for safer resection, even when the tumor abuts structures such as the petrous carotid artery ${ }^{6}$ (as in our case). Familiarity with vascular variations of this region is also critical in planning resection. ${ }^{28}$ Overall recurrence is reported as 20 to $40 \%,{ }^{5,29}$ though correlated with resection. ${ }^{30}$ Modern aggressive skull base resection techniques may improve this rate as noted in several small series. In four patients undergoing total resection, no recurrence was noted at 5 years. ${ }^{3}$ Another five patients treated aggressively showed good long-term control with gross total or near total resection. ${ }^{6}$ Four patients treated with an aggressive transzygomatic approach also showed no recurrence at mean follow-up of 9 years. ${ }^{31}$ In cases of recurrence, repeat resection may still offer acceptable control as well. ${ }^{4,17,32}$ Preoperative embolization has been reported ${ }^{29}$ but is generally not considered for particularly vascular tumors. Radiation is generally not recommended due to the potential for inducing malignant transformation $^{3}$; however, proton beam therapy has been reported with good local control. ${ }^{11,33}$ Metastases for chondroblastoma in general are exceedingly rare and may involve lung or skin. ${ }^{34,35}$

\section{Significance of Translocation of Previously Unreported $t(2 ; 5)(q 33 ; q 13)$ in Temporal Bone Chondroblastoma}

A large series of cytogenetic abnormalities of chondroid tumors from the Chromosomes and Morphology 
(CHAMP) Collaborative Study Group ${ }^{36}$ includes four cases of chondroblastoma arising in extremities, all of which had a normal karyotype. Nonrandom karyotypic aberrations in chondroid tumors reported by CHAMP investigators and others include loss of distal $8 \mathrm{q}$ in osteochondroma; gain of chromosome 5 in chondroma; rearrangements of $6 \mathrm{p}$ and $6 \mathrm{q}$ in chondromyxoid fibroma ${ }^{36-39}$; gains of chromosome 7 ; losses of chromosomes $5 \mathrm{q}, 6 \mathrm{q}$, and $9 \mathrm{p}^{40}$; and abnormalities in $12 \mathrm{q}$ and $17 \mathrm{p}$ in chondrosarcoma ${ }^{41,42}$ and the translocation $(9 ; 22)$ (q22;q12) in extraskeletal myxoid chondrosarcoma. ${ }^{43-46}$ Clonal abnormalities have been reported in typical epiphyseal chondroblastomas, ${ }^{47-52}$ but never to our knowledge in temporal bone chondroblastoma. Loss of chromosome $5 \mathrm{q}$ is a recurring alteration, ${ }^{47-49,51}$ and rearrangement of chromosome $8 \mathrm{q}$ was described in an aggressive or malignant chondroblastoma. ${ }^{49}$ More recently, chondroblastoma was associated with ring chromosome $4,{ }^{50}$ and in a different report with a balanced translocation $(5 ; 17)$ $(\mathrm{p} 15 ; \mathrm{q} 22-23) .{ }^{52}$

\section{CONCLUSION}

In summary, we present a novel clonal abnormality in temporal bone chondroblastoma. This finding opens the possibility to retrospective genomic analysis of previously reported cases to ascertain whether this clonal alteration is diagnostically useful and to understand its role in the pathobiology of this rare skull neoplasm.

\section{REFERENCES}

1. American College of Medical Genetics. Standards and Guidelines for Clinical Genetics Laboratories. Available at:http://www.acmg.net/StaticContent/SGs/Section_E.html. Accessed December 11, 2010

2. Cheng $\mathrm{S}, \mathrm{Ng} \mathrm{T}$, Gomes L, da Cruz M. Temporal bone chondroblastoma. Otol Neurotol 2009;30:688-689

3. Moon IS, Kim J, Lee HK, Lee WS. Surgical treatment and outcomes of temporal bone chondroblastoma. Eur Arch Otorhinolaryngol 2008;265:1447-1454

4. Ishikawa E, Tsuboi K, Onizawa K, et al. Chondroblastoma of the temporal base with high mitotic activity. Neurol Med Chir (Tokyo) 2002;42:516-520

5. Bian LG, Sun QF, Zhao WG, Shen JK, Tirakotai W, Bertalanffy H. Temporal bone chondroblastoma: a review. Neuropathology 2005;25:159-164

6. Kutz JW Jr, Verma S, Tan HT, Lo WW, Slattery WH III, Friedman RA. Surgical management of skull base chondroblastoma. Laryngoscope 2007;117:848-853

7. Hong SM, Park YK, Ro JY. Chondroblastoma of the temporal bone: a clinicopathologic study of five cases. J Korean Med Sci 1999;14:559-564

8. Maruyama R, Nagaoka S, Todaka T, Nakahara T, Kishida K. Intracranial chondromyxoid fibroma extending into the jugular foramen. Pathol Int 1994;44:857-859
9. Narita Y, Morimoto T, Nishikawa R, et al. Chondroblastoma of the temporal bone-report of a case and a review of the literature of 54 cases. No To Shinkei 1992;44:143-148

10. Cabrera RA, Almeida M, Mendonça ME, Frable WJ. Diagnostic pitfalls in fine-needle aspiration cytology of temporomandibular chondroblastoma: report of two cases. Diagn Cytopathol 2006;34:424-429

11. Dran G, Niesar E, Vandenbos F, Noel G, Paquis P, Lonjon M. Chondroblastoma of the apex portion of petrousal bone. Childs Nerv Syst 2007;23:231-235

12. Koerbel A, Loewenheim H, Beschorner R, et al. A 27-yearold woman with cranial nerve dysfunction. Brain Pathol 2007; 17:327-328

13. Kondoh T, Hamada Y, Kamei K, Seto K. Chondroblastoma of the mandibular condyle: report of a case. J Oral Maxillofac Surg 2002;60:198-203

14. Payne M, Yusuf H. Benign chondroblastoma involving the mandibular condyle. Br J Oral Maxillofac Surg 1987;25: 250-255

15. Al-Dewachi HS, Al-Naib N, Sangal BC. Benign chondroblastoma of the maxilla: a case report and review of chondroblastomas in cranial bones. Br J Oral Surg 1980; 18:150-156

16. al-Sader MH, Tait R, Leader M. Chondroblastoma-an unusual site in a young patient. J Laryngol Otol 1996;110: 696-699

17. Bertoni F, Unni KK, Beabout JW, Harner SG, Dahlin DC. Chondroblastoma of the skull and facial bones. Am J Clin Pathol 1987;88:1-9

18. Martinez-Madrigal F, Vanel D, Luboinski B, Terrier P. Case report 670: chondroblastoma maxillary sinus. Skeletal Radiol 1991;20:299-301

19. Muntané A, Valls C, Angeles de Miquel MA, Pons LC. Chondroblastoma of the temporal bone: CT and MR appearance. AJNR Am J Neuroradiol 1993;14:70-71

20. Tanohata K, Noda M, Katoh H, et al. Chondroblastoma of temporal bone. Neuroradiology 1986;28:367-370

21. Leong HK, Chong PY, Sinniah R. Temporal bone chondroblastoma: big and small. J Laryngol Otol 1994;108: 1115-1119

22. Gaudet EL Jr, Nuss DW, Johnson DH Jr, Miranne LS Jr. Chondroblastoma of the temporal bone involving the temporomandibular joint, mandibular condyle, and middle cranial fossa: case report and review of the literature. Cranio 2004;22:160-168

23. Pontius A, Reder P, Ducic Y. Temporal bone chondroblastomas. Am J Otolaryngol 2003;24:370-373

24. Selesnick SH, Levine JM. Chondroblastoma of the temporal bone: consistent middle fossa involvement. Skull Base Surg 1999;9:301-305

25. Ohnishi T, Oku Y, Yamamoto K, Morimura Y, Ushio Y. Benign chondroblastoma of the occipital bone. Surg Neurol $1985 ; 24: 52-56$

26. Horn KL, Hankinson H, Nagel B, Erasmus M. Surgical management of chondroblastoma of the temporal bone. Otolaryngol Head Neck Surg 1990;102:264-269

27. Varvares MA, Cheney ML, Goodman ML, Ceisler E, Montgomery WW. Chondroblastoma of the temporal bone. Case report and literature review. Ann Otol Rhinol Laryngol 1992;101:763-769

28. Ben Salem D, Allaoui M, Dumousset E, et al. Chondroblastoma of the temporal bone associated with a persistent 
hypoglossal artery. Acta Neurochir (Wien) 2002;144:13151318

29. Moorthy RK, Daniel RT, Rajshekhar V, Chacko G. Skull base chondroblastoma: a case report. Neurol India 2002;50:534-536

30. Ionescu DN, McFadden K, Unni KK, Couce ME. Pathologic quiz case: a 33-year-old woman with a large temporal mass. Chondroblastoma of the skull. Arch Pathol Lab Med 2005; 129:539-540

31. Kurokawa R, Uchida K, Kawase T. Surgical treatment of temporal bone chondroblastoma. Surg Neurol 2005;63:265268; discussion 268

32. Blaauw G, Prick JJ, Versteege C. Chondroblastoma of the temporal bone. Neurosurgery 1988;22(6 Pt 1):1102-1107

33. Hug EB, Sweeney RA, Nurre PM, Holloway KC, Slater JD, Munzenrider JE. Proton radiotherapy in management of pediatric base of skull tumors. Int J Radiat Oncol Biol Phys 2002;52:1017-1024

34. Green P, Whittaker RP. Benign chondroblastoma. Case report with pulmonary metastasis. J Bone Joint Surg Am 1975;57: 418-420

35. Seline PC, Jaskierny DJ. Cutaneous metastases from a chondroblastoma initially presenting as unilateral palmar hyperhidrosis. J Am Acad Dermatol 1999;40(2 Pt 2):325327

36. Tallini G, Dorfman H, Brys P, et al. Correlation between clinicopathological features and karyotype in 100 cartilaginous and chordoid tumours. A report from the Chromosomes and Morphology (CHAMP) Collaborative Study Group. J Pathol 2002;196:194-203

37. Granter SR, Renshaw AA, Kozakewich HP, Fletcher JA. The pericentromeric inversion, inv (6)(p25q13), is a novel diagnostic marker in chondromyxoid fibroma. Mod Pathol 1998;11:1071-1074

38. Halbert AR, Harrison WR, Hicks MJ, Davino N, Cooley LD. Cytogenetic analysis of a scapular chondromyxoid fibroma. Cancer Genet Cytogenet 1998;104:52-56

39. Safar A, Nelson M, Neff JR, et al. Recurrent anomalies of 6q25 in chondromyxoid fibroma. Hum Pathol 2000;31:306-311

40. Hameed M, Ulger C, Yasar D, et al. Genome profiling of chondrosarcoma using oligonucleotide array-based comparative genomic hybridization. Cancer Genet Cytogenet 2009; 192:56-59

41. Sandberg AA. Genetics of chondrosarcoma and related tumors. Curr Opin Oncol 2004;16:342-354
42. Sjögren H, Orndal C, Tingby O, Meis-Kindblom JM, Kindblom LG, Stenman G. Cytogenetic and spectral karyotype analyses of benign and malignant cartilage tumours. Int J Oncol 2004;24:1385-1391

43. Stenman G, Andersson H, Mandahl N, Meis-Kindblom JM, Kindblom LG. Translocation $\mathrm{t}(9 ; 22)(\mathrm{q} 22 ; \mathrm{q} 12)$ is a primary cytogenetic abnormality in extraskeletal myxoid chondrosarcoma. Int J Cancer 1995;62:398-402

44. Reid R, de Silva MV, Paterson L. Poorly differentiated extraskeletal myxoid chondrosarcoma with $\mathrm{t}(9 ; 22)$ (q22;q11) translocation presenting initially as a solid variant devoid of myxoid areas. Int J Surg Pathol 2003;11:137-141

45. Kumar R, Rekhi B, Shirazi N, et al. Spectrum of cytomorphological features, including literature review, of an extraskeletal myxoid chondrosarcoma with $\mathrm{t}(9 ; 22)(\mathrm{q} 22 ; \mathrm{q} 12)$ (TEC/EWS) results in one case. Diagn Cytopathol 2008;36:868-875

46. Wang WL, Mayordomo E, Czerniak BA, et al. Fluorescence in situ hybridization is a useful ancillary diagnostic tool for extraskeletal myxoid chondrosarcoma. Mod Pathol 2008;21: 1303-1310

47. Mark J, Wedell B, Dahlenfors R, Grepp C, Burian P. Human benign chondroblastoma with a pseudodiploid stemline characterized by a complex and balanced translocation. Cancer Genet Cytogenet 1992;58:14-17

48. Bridge JA, Bhatia PS, Anderson JR, Neff JR. Biologic and clinical significance of cytogenetic and molecular cytogenetic abnormalities in benign and malignant cartilaginous lesions. Cancer Genet Cytogenet 1993;69:79-90

49. Swarts SJ, Neff JR, Johansson SL, Nelson M, Bridge JA. Significance of abnormalities of chromosomes 5 and 8 in chondroblastoma. Clin Orthop Relat Res 1998;(349):189-193

50. van Zelderen-Bhola SL, Bovée JV, Wessels HW, et al. Ring chromosome 4 as the sole cytogenetic anomaly in a chondroblastoma: a case report and review of the literature. Cancer Genet Cytogenet 1998;105:109-112

51. Papachristou DJ, Goodman MA, Cieply K, Hunt JL, Rao UN. Comparison of allelic losses in chondroblastoma and primary chondrosarcoma of bone and correlation with fluorescence in situ hybridization analysis. Hum Pathol 2006;37:890-898

52. Romeo S, Szuhai K, Nishimori I, et al. A balanced t $(5 ; 17)$ (p15;q22-23) in chondroblastoma: frequency of the rearrangement and analysis of the candidate genes. BMC Cancer 2009;9:393 